\title{
Consumers' Perceived Profit for Online Trading Based on Prospect Theory
}

\author{
Guan Hongjun ${ }^{\mathrm{a}, \mathrm{b}}$, Wang Han ${ }^{\mathrm{b}}$ and Zhao Aiwu ${ }^{\mathrm{c}, *}$ \\ ${ }^{a}$ Central University of Finance and Economic, Beijing 100081, China; ${ }^{b}$ Shandong University of Finance and Economic, \\ Jinan 250014, China; ${ }^{c}$ Jiangsu University, Zhenjiang 212013, China
}

\begin{abstract}
As decision makers of online trading, consumers make trading decisions according to their perceived profit value. Considering both the objective profit value and consumers' trust profit (or loss) value according to the evaluation of historical buyers, this paper proposed an analytic method about perceived profit value based on prospect theory. Firstly, it described the variables related to the calculation of perceived profit value. Next, based on the thought of reference dependent, loss aversion and diminishing sensitivity, it calculated consumers' perceived value according to each evaluation grade. Then, it used the distorted probability judgment thought to achieve the corresponding perceived weight of each evaluation grade according to its statistical probability. Finally, it calculated consumers' total perceived profit value based on the above. An example was illustrated to explain the concrete calculation processes.
\end{abstract}

Keywords: Consumers' trust, Online trading, Perceived profit, Prospect theory.

\section{INTRODUCTION}

Online trading is a new form of the traditional market models in the highly developed information era, representing the future development direction of our society [1]. Online shopping mall with its low price, high quality and efficient service, safe and convenient payment methods get more and more consumers. However, as behavioral decision makers, consumers determine the exact value of online goods based on their own perceived value [2]. When choosing commodities in commerce model, consumers not only prefer the lower price than entity market and the convenience of shopping within doors, but also consider the possible losses because of distrust on the virtual market, that is, they would worry about online sellers' trust because they never communicate to each other face to face. The trust problem referred here not merely referred to malicious fraud, including physical and psychological expectations, delayed delivery, degree of service satisfaction. On the other hand, consumers cannot fully get to know the historical traders' degree of satisfaction of other consumers in entity market. While in a perfect virtual market, historical transaction information and evaluation of purchased goods made by historical traders should be transparent to new visitors. Through the evaluation of businesses and commodities consumers participating in online transactions can understand traders' information, get the perceived trust of each trader, and form the basis for their future trading decision. Therefore, the consumer's transaction decisionmaking process is not only the comparison process of price or objective profit, but also the value of perceived profits according to the comprehensive understanding of the goods and businesses after a kind of analytic process.

*Address correspondence to this author at the Jiangsu university, Zhenjiang 212013, China; Tel: 13325121726; E-mail: aiwuzh@126.com

\section{SUMMARY OF TH RELATED RESEARCH}

At present, many experts and scholars at home and abroad have studied the perceived safety and consumers' psychology under the electronic commerce environment. According to the theory of reasoned action, McKnight et al. (2002) [3] studied people's trust under e-commerce environment, and distinguished the concept of trust willing, trust intention and trust behavior. He believed that in e-commerce context, trust believes include consumers' trust to online businesses and the relevant exception about trust. Through empirical analysis, Jarcenpaa et al. (2000) [4] showed that trust has a positive influence on online purchase attitude. $\mathrm{Li}$ Yi (2007) [5] introduced senses of psychological security concept into the interpretation of network consumers' behavior, and studied the effect of psychological security on consumers' behavior. Yang Lin (2010) [6] took the banking industry as the study object of an empirical study, analyzed the composition of each dimension of psychological contract between enterprise service and customers, and established the model of service enterprises and customers. Wan Yinghong [7] (2011) used the psychological contract theory, by revealing the "responsibility" cognitive of customers to service providers, got conclusions such as customers need and believe that they enjoy "interests and rights". Han Xiaoyun (2012) [8] put forward a model about the relationship of employee service quality and customer satisfaction including customer psychological empowerment. It used multi-level model analysis method, analyzed the just effect of desire to control customers' psychological empowerment and customers' satisfaction. At the same time, the study of customers' perceived profit value has been growing, Jilian et al. (2001) [9] analyzed the customer perceived value from the whole value angle, and put forward the four value dimensions through an empirical research. The article [10-15] focused on consumers' perceived value and purchased intention, the re- 
lationship between brand planning and brand loyalty, and relationship quality [10-12]. It explained the purchase intention and customer retention through empirical research [1315]. Taking mobile service consumption as an example, the article [16] highlighted the actual dimensions of customer perceived value by empirical analysis. Also, it studied the relationship among the intention of purchasing, brand planning and brand loyalty [16]. The literature [17-20] studied consumers' perceived value under the environment of electronic commerce, and detailed their purchase decision, buying behavior, intention interaction and information search on shopping [17-20]. In fact, study of consumers' psychology and consumers' perceived profit value earns more and more attention, but from the consumers' point of view, no researcher has been found to describe the perceived profit value based on quantitative analysis using prospect theory. Prospect theory [21,22], as a descriptive model for risk decision making, is used to explain the reason of decision making under risk environment in behavioral science research. It can be used to describe the reference dependence, loss of aversion and distorted probability judgment, and other decisionmaking behavioral characteristics [23]. The theory can be used as a theoretical tool for the analysis of perceived profit of online consumers.

\section{SCENE DESCRIPTION AND RELEVANT VARIA- BLES}

Suppose that consumers are decision makers using prospect theory, who determine the online transactions according to their perceived profit value. Businesses provide online real-time trust evaluation information of historical traders, and the trust evaluation is divided into grades.

(1) $D=\left(d_{1}, d_{2}, \ldots d_{n}\right)$ : Trust evaluation is divided into $\mathrm{n}$ grades (such as very satisfied, satisfied, ordinary, unsatisfied etc.). Higher grade represents worse trust evaluation.

(2) $P=\left(p_{1}, p_{2}, \ldots p_{n}\right):$ Trust evaluation $d_{j}$ 's corresponding statistical probability, was given by the data evaluation from historical consumers when they completed their transactions. Obviously, $\sum_{i=1}^{n} p_{i}=1$.

(3) $L=\left(l_{1}, l_{2}, \ldots l_{n}\right)$ : The amount of evaluation grade $d_{j}$ 's corresponding loss of consumers' trust. These are experimental values, such as the loss is 0 when the trust grade is very satisfied, otherwise is negative. That is $l_{j} \leq 0$, 且 $l_{1} \leq l_{2} \leq \ldots \leq l_{n}(j=1,2, \ldots n)$.

(4) $\tilde{s}$ : Consumers' ideal profit for normal online trading, which includes cheaper price comparison with the entity mall, saving transportation costs and saving times. Due to the regional differences and the information asymmetry, the perception of consumers' profit is not a fixed value, so it is defined as an interval value, that is $\tilde{s}=\left[s^{L}, s^{U}\right]$, and $s^{U} \geq s^{L}$.

(5) $S^{R}$ : Consumers' expected profit. Consumers usually have their certain profit expectations of online shopping.
That expected profit might be price advantage compared with the real market, or other intangible profits such as saving times, etc. When the actual profit of online transaction is greater than consumers' expected profit, consumers feel as "income", on the other hand, feel as "loss". The expected profit is also considered as a consumer's "reference point" reflecting consumers' psychological behavior character of reference dependence, so $s^{R} \geq 0$.

(6) g: When facing some trust evaluation grades, consumers will ignore the income part, and only consider the loss ones. In extreme cases such as fraud, consumers will not consider the profit better than shopping in the entity mall. In other words, $g$ is the loss of consumers' psychological endurance limit, when an evaluation grade is poor enough to a certain level, consumers will ignore the actual income outside trust.

According to above variables and based on prospect theory, considering consumers' psychological and behavioral characteristics, such as reference dependence, loss aversion, diminishing sensitivity and distorted probability judgment, and so on, we will analyze and calculate consumers' perceived profit value of online transactions.

\section{CACULATION OF PERCEIVED PROFIT VALUE}

Because each evaluation grade corresponds to a different profit and loss, the first step is to calculate the comprehensive prospect value for each trust grade. Then we will calculate the distorted probability perception according to statistical probability of each grade, which is also the weight of evaluation grade. Finally, total prospect values are calculated based on the results obtained, which are perceived profit value of consumers.

\subsection{Calculation of Each Trust Grade's Comprehensive Prospect Value}

According to decision makers' psychological and behavioral characteristics of reference dependence, loss aversion, and diminishing sensitivity, based on prospect theory [2428], the calculation method of comprehensive prospect value for each grade is given below.

According to consumers' psychological and behavioral character of reference dependence, consumers perceived incomes or losses of a transaction is compared with their reference points. When the loss is lower than consumers' psychological max value, namely $\mathrm{j}<\mathrm{g}$, the income and loss value of evaluation grade $d_{j}$ relative to reference point $s^{R}$ is:

$$
\begin{aligned}
& \tilde{e}_{j}=\tilde{s}+l_{j}-s^{R}=\left[s^{L}+l_{j}-s^{R}, s^{U}+l_{j}-s^{R}\right]=\left[e_{j}^{L}, e_{j}^{U}\right] \\
& j=1,2, \ldots, n
\end{aligned}
$$

From (1-1), $\tilde{e}_{j}=\left[e_{j}^{L}, e_{j}^{U}\right]$ is also an interval number. If $e_{j}^{L}>0$, then the profit value of $\mathrm{j}$ grade is more than $s^{R}$, which consumers perceive as income. On the other hand, if $e_{j}^{U}<0$, then the profit value of $\mathrm{j}$ grade is less than $S^{R}$, which 
consumers perceive as the loss. If $e_{j}^{L} \leq 0 \leq e_{j}^{U}$, then the profit value may be greater or less than the reference point, so consumers' psychological perception may be income or loss.

When $j \geq g$, part $\tilde{S}$ will be reduced during the calculation of profit value of grade $d_{j}$ comparison with the reference point $S^{R}$, that means, consumers will ignore the objective income in these cases:

$e_{j}=l_{j}-s^{R}$

From (1-2), the psychological perception of consumers is definitely "loss".

To calculate the comprehensive psychological perceived profit value of grade $d_{j}$, for $\mathrm{j}<\mathrm{g}$, assuming $e_{j}$ is a random variable in the range of $\left[e_{j}^{L}, e_{j}^{U}\right], f_{j}\left(e_{j}\right)$ is a probability density function of $e_{j}$. As the interval number $\tilde{s}$ is due to consumers' different geographical factors, $f_{j}\left(e_{j}\right)$ can be considered as an average distribution. That is:

$f_{j}\left(e_{j}\right)=\frac{1}{e_{j}^{U}-e_{j}^{L}}$

The costumers' perceived loss value $(\mathrm{j}<\mathrm{g})$ is:

$$
v_{j}= \begin{cases}\int_{e_{j}^{L}}^{e_{j}^{U}} v^{+}\left(e_{j}\right) f_{j}\left(e_{j}\right) d e_{j} & e_{j}^{L}>0 \\ \int_{0}^{e_{j}^{L}} v^{-}\left(e_{j}\right) f_{j}\left(e_{j}\right) d e_{j}+\int_{0}^{e_{j}^{U}} v^{+}\left(e_{j}\right) f_{j}\left(e_{j}\right) d e_{j} & e_{j}^{L} \leq 0 \leq e_{j}^{U} \\ \int_{e_{j}^{U}}^{e_{j}^{L}} v^{-}\left(e_{j}\right) f_{j}\left(e_{j}\right) d e_{j} & e_{j}^{U}<0\end{cases}
$$

While for $\mathrm{j} \geq \mathrm{g}$,

$v_{j=} v^{-}\left(e_{j}\right)$

$v^{-}\left(e_{j}\right)$ represents the perceived loss when $e_{j} \leq 0$, while $v^{+}\left(e_{j}\right)$ represents the perceived income when $e_{j} \geq 0$. According to the idea of prospect theory, the formulas of $v^{-}\left(e_{j}\right)$ and $v^{+}\left(e_{j}\right)$ are:

$v^{-}\left(e_{j}\right)=-\lambda\left(-e_{j}\right)^{\beta}, \quad e_{j} \leq 0, j=1,2, \ldots n$

$v^{+}\left(e_{j}\right)=\left(e_{j}\right)^{\alpha}, \quad e_{j} \geq 0, j=1,2, \ldots n$

$\alpha$ and $\beta(0 \leq \alpha, \beta \leq 1)$ represent the concave and convex degree of value function for "income" and "loss". Greater $\alpha$ and $\beta$ represent higher concave and convex degree of consumers' value function of "income" and "loss", which reflects the psychological and behavioral characteristics of consumers' decreasing income sensitivity. Parameter $\lambda>1$ embodies the fact that when facing "loss', consumers are more sensitive than facing "income" (psychological and behavioral decision characteristic named "loss aversion"). The more consumers involved in loss aversion degree, the greater $\lambda$ is. According to articles [24-28], usually we take $\alpha=0.89, \beta=0.92$ and $\lambda=2.25$.
Through feed formulas (4-1), (4-2), (2) and the parameter values obtained into (3-1), we get consumers' perceived income value $(\mathrm{j}<\mathrm{g})$ :

$$
v_{j}=\left\{\begin{array}{lr}
\frac{\left(e_{j}^{U}\right)^{1.89}-\left(e_{j}^{L}\right)^{1,89}}{1.89\left(e_{j}^{U}-e_{j}^{L}\right)} & e_{j}^{L}>0 \\
\frac{-2.25\left(-e_{j}^{L}\right)^{1.92}}{1.92\left(-e_{j}^{L}\right)}+\frac{\left(e_{j}^{U}\right)^{1.89}}{1.89 e_{j}^{U}} & e_{j}^{L} \leq 0 \leq e_{j}^{U} \\
\frac{-2.25\left[\left(-e_{j}^{L}\right)^{1.92}-\left(-e_{j}^{U}\right)^{1.92}\right]}{1.92\left(e_{j}^{U}-e_{j}^{L}\right)} & e_{j}^{U}<0
\end{array}\right.
$$

While when $\mathrm{j} \geq_{\mathrm{g}}$,

$v_{j=}-2.25\left(-e_{j}\right)^{0.92}$

$v_{j}$ is consumers' corresponding perceived profit value of $\mathrm{j}$ grade.

\subsection{Calculation of Perceived Probability for Each Evalu- ation Trust Grade}

According to prospect theory, based on decision makers' psychological behavioral characteristic such as distorted probability judgment, first of all, the research gives the weight calculation method for each trust grade in the general perceived profit value:

In descending order $v_{1}, v_{2}, \ldots v_{n}$, get $v_{1} \geq \ldots \geq v_{h} \geq 0 \geq v_{h+1} \geq v_{n}$. Clearly, if $\mathrm{j} \leq_{\mathrm{h}}, v_{j} \geq 0$, else $v_{j} \leq_{0}$. According to the idea of prospect theory, the weight of perceived profit of grade $j$ in consumers' comprehensive perceived profit is:

$\pi_{j}= \begin{cases}\omega^{+}\left(\sum_{i=1}^{j} p_{i}\right)-\omega^{+}\left(\sum_{i=1}^{j-1} p_{i}\right), & j=1,2, \ldots h \\ \omega^{-}\left(\sum_{i=j}^{n} p_{i}\right)-\omega^{-}\left(\sum_{i=j+1}^{n} p_{i}\right), & j=h+1, h+2, \ldots h\end{cases}$

In formula (6), function $\omega^{+}(\cdot)$ and $\omega^{-}(\cdot)$ are nonlinear weight function for "income" and "loss" respectively. According to articles [24-28], function $\omega^{+}(\cdot)$ and $\omega^{-}(\cdot)$ respectively are:

$$
\begin{aligned}
& \omega^{+}(p)=\frac{p^{x}}{p^{x}+(1-p)^{1 / x}} \\
& \omega^{-}(p)=\frac{p^{\delta}}{p^{\delta}+(1-p)^{1 / \delta}}
\end{aligned}
$$

In this model, parameter $x=0.61, \delta=0.69$.

Further, in order to make the ultimate comprehensive profit value standard, we normalize the weight $\pi_{j}$, to obtain the perceived probability of consumers and the perceived probability of total is still 1 . Then:

$$
\bar{\pi}_{j}=\pi_{j} / \sum_{i=1}^{n} \pi_{i}
$$


Table 1. Trust evaluation grades for online seller.

\begin{tabular}{|c|c|c|c|}
\hline Trust Grade $d_{j}$ & Trust Evaluation & Profit Value $l_{j}$ & Statistical Probability $p_{i}$ \\
\hline \hline 1 & Good & 0 & $60 \%$ \\
\hline 2 & Satisfied & -5 & $30 \%$ \\
\hline 3 & Ordinary & -10 & $9 \%$ \\
\hline 4 & Poor & -50 & $1 \%$ \\
\hline
\end{tabular}

Table 2. Perceived profit value and weight of each trust grade.

\begin{tabular}{|c|c|c|c|}
\hline Trust Grade $d_{j}$ & Reference Profit $\tilde{e}_{j}$ & Perceived Profit $v_{j}$ & Weight $\bar{\pi}_{j}$ \\
\hline \hline 1 (good) & {$[5,15]$} & 7.73 & $65.64 \%$ \\
\hline 2(satisfied) & {$[0,10]$} & 4.11 & $17.91 \%$ \\
\hline 3(ordinary) & {$[-5,5]$} & -2.94 & $12.97 \%$ \\
\hline 4 (poor) & -50 & -82.27 & $3.47 \%$ \\
\hline
\end{tabular}

$\bar{\pi}_{j}$ is the perceived probability of grade $\mathrm{j}$ when calculating comprehensive profit value.

\subsection{Calculation of Consumers' Total Perceived Profit Value}

According to the perceived profit value and perceived weight of each trust grade calculated above, the formula of consumers' overall perceived profit value is as follows:

$$
E_{v}=\sum_{j=1}^{n} v_{j} \bar{\pi}_{j}
$$

\section{CASE ANALYSIS}

In order to illustrate the real process to calculate consumers' total perceived profit value, we chose a certain type of goods of a certain online seller. The expected trust profit $\tilde{S}$ of the seller is $[5,15]$, the evaluation results have been divided into 4 grades, respectively, good, satisfied, ordinary, poor, $g=4$, i.e. when the trust evaluation grade is poor, consumers would only consider loss as they calculate their perceived profit value, and consumers' expected profit is 0 . The profit value of each grade and the cumulative statistical probability of historical transactions are showed in Table 1:

According to the previous calculation method, perceived profit values and their weight for each trust grade are given in Table 2:

According to formula (9), the final result is $E_{v}=2.57$, which means that consumers' overall perceived profit value is 2.57 , and the overall perception of consumers is performed as "income". At this point, consumers' perceived profit value was obtained based on quantization considering their psychological and behavioral characteristics. At the same time, because the perceived profit value is "loss", the perceived weight of $9 \%$ ordinary grade and $1 \%$ poor grade is distorted to $12.97 \%$ and $3.47 \%$ respectively, which are amplified in different degrees. The results completely conform to the psychological and behavioral characteristics of decision makers under prospect theory. Similarly, as to the grades whose reference interval is positive, the perceived profit values are less than the average reference profit (i.e., good: $7.73<10$, satisfied: $4.11<5$ ). While to the negative grades, the perceived losses are greater than the average reference loss (ordinary: $-2.94<0$, poor: $-82.27<-50$ ). These results also reflect the prospect theory about loss avoidance and decreasing sensitivity. The instance remind online sellers pay full attention to every consumer's every bad evaluation, because the effect of a negative evaluation on future potential trading is far more important than the number itself.

\section{CONCLUSION}

Based on prospect theory, this paper put forward a method to calculate consumers' comprehensive perceived profit value for online trading. This method is based on the prospect theory of value function and weight function, instead of utility function and probability based on traditional expected utility theory. It fully embodies consumers' psychological and behavioral characteristics as online decisionmakers, such as reference dependence, loss aversion, diminishing sensitivity, distorted probability judgment, and so on. Therefore, this method considers consumers' psychological factors, and quantifies it to the total value of consumers' perceived profit.

\section{CONFLICT OF INTEREST}

The authors confirm that this article content has no conflict of interest.

\section{ACKNOWLEDGEMENTS}

This work is supported by the Fund of the Ministry of Education of Humanities and Social Sciences 
(No.14YJAZH025), China Postdoctoral Science Foundation (No.2013M530862, No.2014M551525), the Natural Science Foundation of Shandong Province (No.ZR2013GM003), and the Jiangsu Postdoctoral Research Grants Program (No.1302056C). The authors are grateful to the anonymous referee for carefully verifying the details and for providing helpful comments that improved this paper.

\section{REFERENCES}

[1] K. Xiao, "Electronic commerce credit intermediary architecture and function of economic analysis," Commercial Research, vol. 340, pp.138-145, 2006.

[2] W. Liu, and R. Chen, "The theory of customer value concept model," Market Modernization, 31, no.11, pp. 47-48, 2008.

[3] D. McKnight, and N. Chervany, "What trust means in e-commerce customer relationships: an interdisciplinary conceptual typology," International Journal of Electronic Commerce, vol. 6, no.2, pp. 3559, 2002.

[4] S. Jarcenpaa, N. Tractinsky, and M. Vitale, "Consumer trust in an internet store," Information Technology and Management, vol. 1, no.1/2, pp. 45-71, 2000

[5] Y. Li, and Q. Ma, "Effect of Customers' Psychological Safety Perception on Their Behaviors in Internet Services," Chinese Journal of Management, vol. 06, no. 4, pp. 796-802, 2007.

[6] L. Yang, "Study on Psychological Contract Structure between the Service Enterprise and Customer: An Empirical Test Based on Banking Industry," Nankai Business Review, vol. 1, no. 13, pp. 5968+89, 2010.

[7] Y. Wan, Y. Yue, and L. Jiang, "New Perspective on Customer Implicit Demand under the Service Relationship:-Based on Business Responsibility Dimensions in Customer Psychological Contract," Forecasting, vol. 5, no. 30, pp. 6-12, 2011.

[8] X. Han, Y. Li, "A Multi-level Model Research on Customer Psychological Empowerment: The Moderated Effect of Desire of Control," Nankai Business Review, vol. 15, no. 3, pp. 4-11, 2012.

[9] J. C. Sweeney, and G. N, Soutar, "Consumer Perceived Value: The Development of a Multiple Item Scale," Journal of Retailing, vol. 77, pp. 203-220, 2001.

[10] J. Chen, K. Liu, and Y. Song, "Impacts of the Reference Group on the Perception value of Costumer and the wellness of their Purchase," Shanghai Management Science, vol. 3, pp. 25-30, 2006.

[11] B. Ma, J. Li, C. Li, and G. Wang, "Value Perception of Reward Programs and Its Effects on Program Loyalty and Brand Loyalty," Nankai Business Review, vol. 9, no. 5, pp. 41-51, 2006.

[12] J. Liu, "Discussion on the Effects of Determinants of Perceived Value on Relationship Quality," Soft Science, vol. 22, no. 5, pp. 1822, 2008.

[13] D. Zhao, and S. Ji, "Trust and Perceived Risk to Online Purchase Intention:An Empirical Study," Journal of Applied Statistics and Management, vol. 29, no. 2, pp. 305-314, 2010.
[14] Y. Zhou, W. Meng, H. Du, and P. Wu, "Value-based adoption of MDS:an empirical investigation," Journal on Communications, vol. 29, no. 9, pp. 97-102+110, 2008.

[15] J. Ma, C. L1, and Z. Zhu, "Impact of the Value Perception of the Reward Programs on Customer Retention," Forecasting, vol. 30, (no. 5, pp. 13-17, 2011.

[16] Q. Chen, and Q. Chen, "Empirical Study on Factual Dimensions of Consumer Perceived Value-Take Mobile Service Consumption as an Example," Journal of Beijing University of Posts and Telecommunications(Social Sciences Edition), vol. 13, no. 3, pp. 63-71, 2011.

[17] C. Wang, Y. L1, and Q. Ye, "Research into Network Consumers' Decision Behavior Based on Perceived Value in E-shopping Environment," Forecasting, vol. 26, no. 3, pp. 21-25+60, 2007.

[18] X. Lei, and W. Zhang, "Influence of Customer Perceived Value on Purchase Behavior and Enterprise Future Sales on Electronic Commerce Platform," Shanghai Management Science, vol. 34, no. 4, pp. 27-33, 2012.

[19] W. Zhang, and X. Le1, "The Impacts of E-commerce Interactivity on Customer Perceived Value," Mathematics in Practice and Theo$r y$, vol. 42, no.11, pp. 69-75, 2012.

[20] W. Hu, Y. Jin, and J. L1, "The Impact of Perceived Value of Information Searching on Customers' Internet Purchase Willingness," Journal of Beijing University of Posts and Telecommunications(Social Sciences Edition), vol. 13, no. 3, pp. 31-37, 2011.

[21] D. Kahneman, and A. Tversky, "Prospect Theory: An analysis of decision under risk," Econometrica, vol. 47, no. 2, pp. 263-291, 1979.

[22] A. Tversky, and D. Kaheman, "Advances in Prospect Theory: Cumulative representation of uncertainty," Journal of Risk and Uncertainty, vol.5, no.4, pp. 294-323, 1992.

[23] Z. Fan, Y. Liu, and R. Shen, "Risk decision analysis method for emergency response based on prospect theory," Systems Engineering-Theory \& Practice, vol. 32, no. 5, pp. 977-984, 2012.

[24] T. Langer, and M. Weber, "Prospect theory, mental accounting, and differences in aggregated and segregated evaluation of lottery portfolios," Management Science, vol. 47, no.5, pp. 716-733, 2001.

[25] H. Bleichrodt, U. Schmidt, and H. Zank, "Additive utility in prospect theory," Management Science, vol. 55, no. 5, pp. 863-873, 2009.

[26] P. W. Chen, W. Y. Lin, T. H. Huang, and W.T. Pan, "Using Fruit Fly Optimization Algorithm Optimized Grey Model Neural Network to Perform Satisfaction Analysis for E-Business Service," Applied mathematics \& information sciences, vol. 7, no.2, pp. 459465, 2013.

[27] Y. He, and J. Weng, "Decision-Making through Uncertain Linguistic Information by Multi-attribute Group: Concerning Credit Guarantee Products Risk," Applied mathematics \& information sciences, vol. 8, no.1, pp. 401-406, 2014.

[28] Y. Yao, "Credit Risk Assessment of Online Shops Based on Fuzzy Consistent Matrix," Applied mathematics \& information sciences, vol. 5, no. 2, pp. 163-169, 2011.

(C) Hongjun et al.; Licensee Bentham Open.

This is an open access article licensed under the terms of the (https://creativecommons.org/licenses/by/4.0/legalcode), which permits unrestricted, noncommercial use, distribution and reproduction in any medium, provided the work is properly cited. 